\title{
Optical and Electrical Characteristics of an Endoscopic DBD Plasma Jet
}

\author{
Orianne Bastin, ${ }^{a, *}$ Max Thulliez, ${ }^{a}$ Jean Servais, ${ }^{a}$ Antoine Nonclercq, ${ }^{a}$ \\ Alain Delchambre, ${ }^{a}$ Alia Hadefi, ${ }^{b}$ Jacques Devière,${ }^{b}$ \& François Reniers ${ }^{c}$ \\ aBio-, Electro-, and Mechanical Systems (BEAMS), Biomed Group, Ecole Polytechnique \\ de Bruxelles, Brussels, Belgium; 'Department of Gastroenterology, Hepatopancreatology, \\ and Digestive Oncology, C.U.B. Erasme Hospital, Université Libre de Bruxelles, Brussels, \\ Belgium; 'Chemistry of Surfaces, Interfaces, and Nanomaterials, ChemSIN, Université Libre de \\ Bruxelles, Faculty of Sciences, Brussels, Belgium \\ *Address all correspondence to: Orianne Bastin, Bio-, Electro-, and Mechanical Systems (BEAMS), Biomed Group, \\ Ecole Polytechnique de Bruxelles, Brussels, Belgium; Tel.: +32 265028 38, E-mail: Orianne.bastin@ulb.ac.be
}

\begin{abstract}
In this work, a new cold plasma source design capable of generating and transporting a plasma jet over long distances $(2 \mathrm{~m})$ is presented with the purpose of being used in flexible endoscopy for treatment within the gastrointestinal tract. This dielectric barrier discharge helium plasma jet consists of a polytetrafluoroethylene capillary connected to a quartz chamber around which a copper electrode is wrapped. A copper wire is freely inserted inside the capillary. The applied voltage is a conventional AC 18-kHz signal to drive the discharge. In order to develop a safe and predictable treatment, a robust and reliable electrical model is necessary and we hypothesized that plasma transport can be modeled as a transmission line. We therefore assessed the electrical behavior of our new cold plasma source. As it is known that the target to which the plasma jet is applied drastically changes the behavior of the plasma itself, an electrical substitute simulating the impedance of a human body is introduced into the circuit, and the plasma behavior is then compared to the free-jet configuration. The effects of the input power (from $10 \mathrm{~W}$ to $80 \mathrm{~W}$ ), and the length of the jet (from $60 \mathrm{~cm}$ to $220 \mathrm{~cm}$ ) were investigated, as well as the electrical changes induced by the presence of an endoscope. The results obtained show trend curves similar to our hypothetical model, although the latter is still only qualitative. This long plasma jet model represents a promising approach that can be used, after further refinement, for controllability of plasma jets for endoscopy applications.
\end{abstract}

KEY WORDS: cold atmospheric plasma, electrical characterization, optical characterization, plasma jet, endoscopy, dielectric barrier discharge

\section{INTRODUCTION}

Interest in the use of cold atmospheric plasma (CAP) for medical applications has been growing over the last two decades..$^{1-3}$ In addition to electrons, ions, ultraviolet radiation, and electromagnetic fields, CAP produces highly reactive species (RS) that have important oxidative (among other) effects on living cells without inducing thermal damage at the treatment site, because its temperature is close to ambient temperature. Reactive oxygen species (ROS), in particular, have been shown to have various biological effects on cells, such as the triggering of programmed cell death (apoptosis), that can reduce tissue inflammation ${ }^{4,5}$ and may represent a powerful tool for treatment of tissues and potentially reduce postoperative complications. 
The scope of plasma medicine applications is broad. Various studies have reported the use of cold plasma for treatment of malignant or dysplastic lesions, ${ }^{6,7}$ for promoting wound healing, ${ }^{8}$ for achieving haemostasis,${ }^{9}$ and for inducing cell regeneration. ${ }^{10}$ Some of this research has already led to the development of medical devices such as the kINPenMED $^{\circledR}$ (Neoplas Tools GmbH $)^{11}$ and the PlasmaDerm ${ }^{\circledR}$ (CINOGY System GmbH), ${ }^{12}$ which are currently available on the market.

Recent advances in therapeutic endoscopy have made it possible to treat multiple diseases through endoluminal, minimally invasive surgery. ${ }^{13-17}$ Consequently, the administration of cold plasma via endoscopy has been proposed over the last decade. ${ }^{18-20}$ However, major medical and technological constraints must be overcome in order to implement this in practice. For example, in addition to the geometric requirements of the gastrointestinal tract, one must be able to bring the plasma inside the body in a manner that is biologically effective, stable, controllable, and safe, while keeping the power generator and the high-voltage plasma electrode outside the patient's body. Meeting these requirements is not trivial, especially since the behavior and effect of the plasma are highly dependent on the target itself (the patient) and on the overall electrical configuration of the system. ${ }^{21-23}$ Therefore, each plasma source needs to be characterized extensively for each new device configuration.

In this work, we first present a new system configuration that allows the generation of cold plasma through dielectric barrier discharge (DBD) in a helium gas flow, and allows the transport of this plasma, postdischarge, over more than $2 \mathrm{~m}$ through a capillary fitting in an endoscope (Fig. 1). At least three other plasma systems have been developed by other groups for endoscopy. These include the GREMI group's plasma gun, which targets local cancer therapy with a nanopulsed neon plasma flushed through a capillary that can fit into an endoscope; ${ }^{18,24,25}$ Winter et al.'s ${ }^{19,26,27}$ device, which consists of argon CAP delivered through a flexible endoscopy device; and Takamatsu et al.'s ${ }^{9}$ device, which is used for hemostasis in vivo. The system presented in this paper allows the generation of a plasma plume brighter and further away from the plasma source, with the advantage of keeping the high-voltage electrode outside the endoscope and therefore far away from the patient's body.

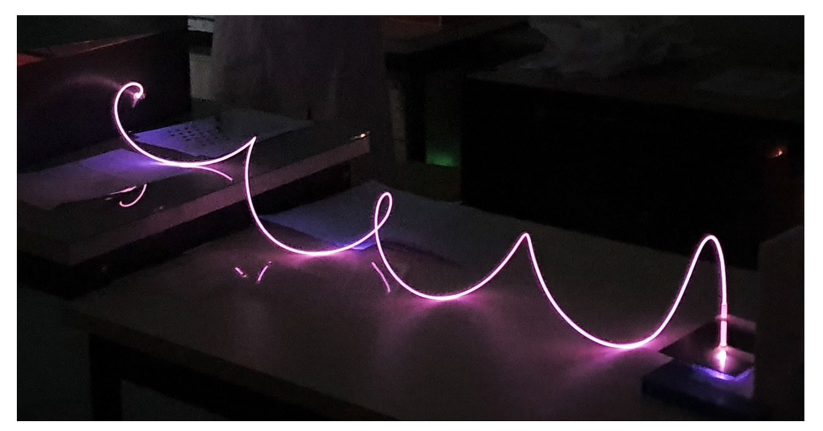

FIG. 1: Cold plasma generation and transport over a long distance 
To tackle the medical need for predictability and safety, we suggest an electrical model for the capillary plasma jet, and to confirm it we study the behavior of this device by optical emission spectroscopy and electrical analysis. The influence of the target on the plasma behavior is highlighted by a comparison between a configuration in free jet and a configuration in which the plasma jet is applied to a target mimicking human impedance. ${ }^{28}$ The impacts of input power and gap between the capillary outlet and the target are discussed. Finally, modifications in the behavior of the plasma induced by the endoscope are assessed.

\section{EXPERIMENTAL}

\section{A. Plasma Reactor}

The plasma reactor used in this work is depicted in Fig. 2. Its core consists of a tubular DBD chamber made of quartz (outer diameter of $7 \mathrm{~mm}$, inner diameter of $5 \mathrm{~mm}$ ) connected upstream to a helium gas cylinder, an admission valve, and a flowmeter. The high-voltage electrode consists of a copper tape wrapped around the chamber over 3 $\mathrm{cm}$. The power-controlled source (AC-sinusoidal) is an AFS (G10S-V) generator, operating at $18 \mathrm{kHz}$. Although no difference is observed when present or not, the ground electrode is connected upstream at the inlet of the discharge chamber (on a stainless steel fitting located $20 \mathrm{~cm}$ away from the copper electrode). The chamber is plugged in to a polytetrafluoroethylene (PTFE) tube (with an outer diameter of $3 \mathrm{~mm}$ to enter the endoscope and a wall thickness of $0.75 \mathrm{~mm}$ to ensure electrical insulation) transporting

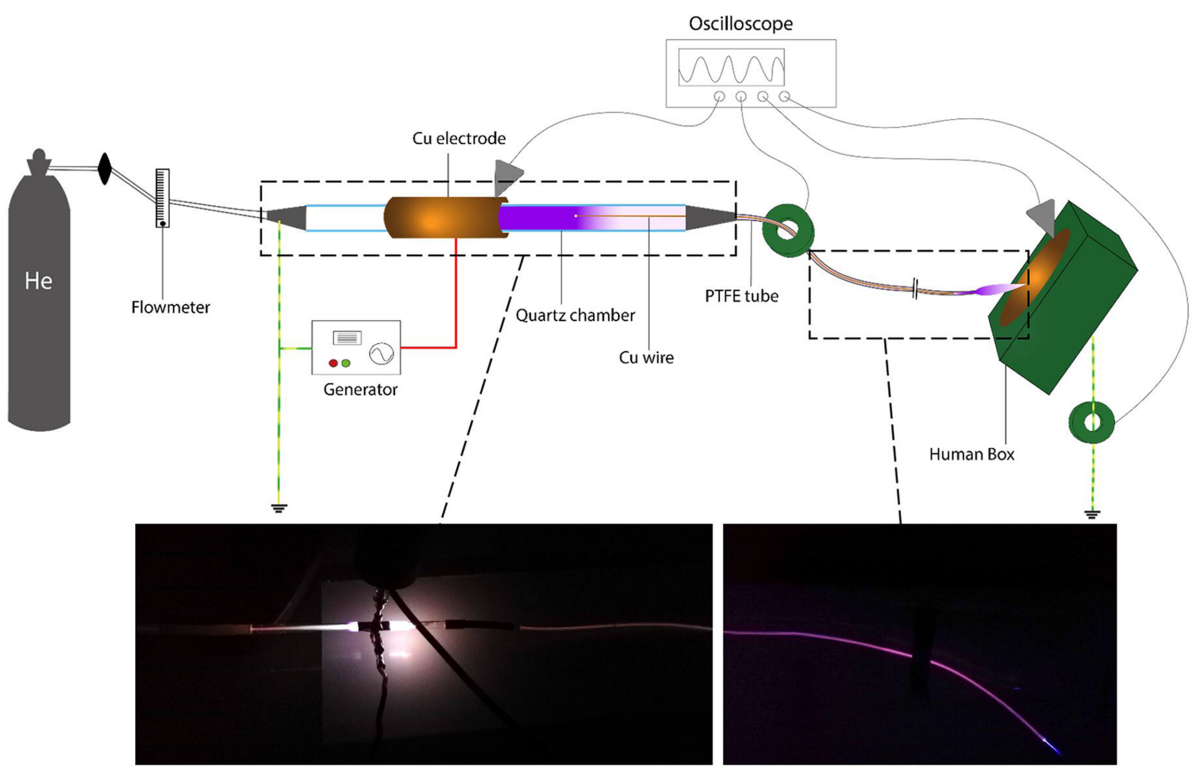

FIG. 2: DBD reactor 
the plasma postdischarge over $2 \mathrm{~m}$. The fluidic connection between the quartz chamber and the PTFE capillary is via a heat-shrinkable insulating sleeve. A copper wire $(0.2$ $\mathrm{mm}$ in diameter) is inserted partially into the dielectric chamber and extends until the end of the PTFE tube to allow the maintenance of active plasma for several meters and to sustain a plasma plume at the outlet even at low power (as low as $10 \mathrm{~W}$ ). The copper wire lies $1 \mathrm{~cm}$ downstream from the electrode and runs inside the PTFE capillary up to $5 \mathrm{~mm}$ before the capillary's end.

In order to mimic the electrical impedance of the human body, a specific target based on the work of Stancampiano et al. ${ }^{28,29}$ is built and placed at the output of the PTFE tube. This target, referred to as the "human box" in this paper, consists of a box with a copper disk connected to an electrical circuit, as shown in Fig. 3, and connected to ground.

\section{B. Measurement Setup}

Electrical measurements (Fig. 2) were collected with a WaveSurfer 3024z oscilloscope connected to high-voltage probes (Tektronix P6015A $\times 1,0003 \mathrm{pF} 100 \mathrm{MOhms}$ ) placed at the high-voltage electrode and at the entrance of the human box (represented as triangles in Fig. 2). Two current monitors (Rogowski coil Pearson model 2877 output $1 \mathrm{~V} / \mathrm{A}$ and 6595 output 2V/A) are placed along the PTFE tube and after the human box (circle in Fig. 2).

Standard parameters are the following: the input power is set at $50 \mathrm{~W}$; the PTFE tube length is equal to $2 \mathrm{~m}$; and the distance between the catheter tip and the human box is 1 $\mathrm{cm}$. Current along the tube means the current measured by the Rogowski coil around the PTFE tube and placed $20 \mathrm{~cm}$ further away from the right end of the high-voltage electrode. This distance from the electrode will influence the current along the tube measure. Voltage at the plume means the voltage at the input of the human box with regard to the ground. Current at the plume is the current passing through the human box.

When the system is in free-jet mode (without the human box), voltage at the plume and current at the plume are not registered, as the measurement probes disturb the behavior of the whole system (the configuration is no longer "free jet"). RMS currents were computed in MATLAB using the root-mean-square function over one period.

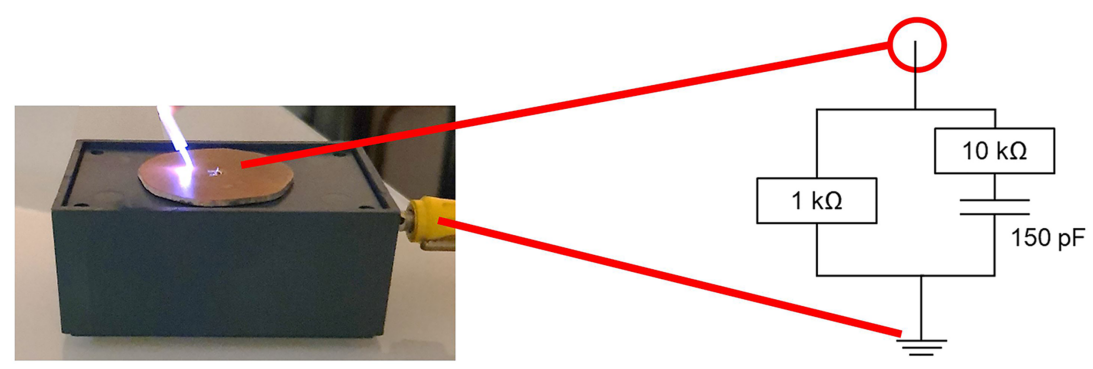

FIG. 3: Human box approaching electrical impedance of the human body based on Stancampiano et al. ${ }^{28}$ 
Pictures were taken with a Nikon D90+ camera operating in manual mode, manual focus, ISO 1,000, shutter speed $1 \mathrm{~s}$, focal 8 in a dark room. Optical emission spectroscopy (OES) is carried out with an Andor Technology SR-500i-D2-R spectrometer, with an acquisition time of $0.05 \mathrm{~s}$ repeated 10 times. The probe position is shown in Fig. 4.

The endoscope used in these tests is an Olympus CF Q160AI Colonoscope with a 3.7$\mathrm{mm}$ working channel, an outer diameter of $12.8 \mathrm{~mm}$, and a 1,330-mm-long working part.

\section{Model}

On the basis of a first exploratory review of this device, including electrical measurements and testing to acquire a better understanding of its function, an electrical model of our system is hypothesized (as shown in Fig. 5). As detailed in the device description, the quartz DBD chamber is connected to a PTFE capillary in which a copper wire is floating. Therefore, we have a concentric configuration, with its core made of copper, a second layer made of helium cold atmospheric plasma, a third layer of PTFE, and, finally, the surrounding ambient air. Copper wire and ignited helium plasma can be reasonably modeled by a resistor. The PTFE layer (a dielectric material) isolates the conductive copper wire and ignited helium plasma from its surrounding (in particular, the ground through the ambient air) and hence can be modeled as a capacitor, from which leakage current can flow through capacitive coupling all along the capillary.

This configuration can be seen as a transmission line,,$^{30,31}$ typically used in cables (e.g., coaxial cables) designed to conduct high-frequency alternating current;

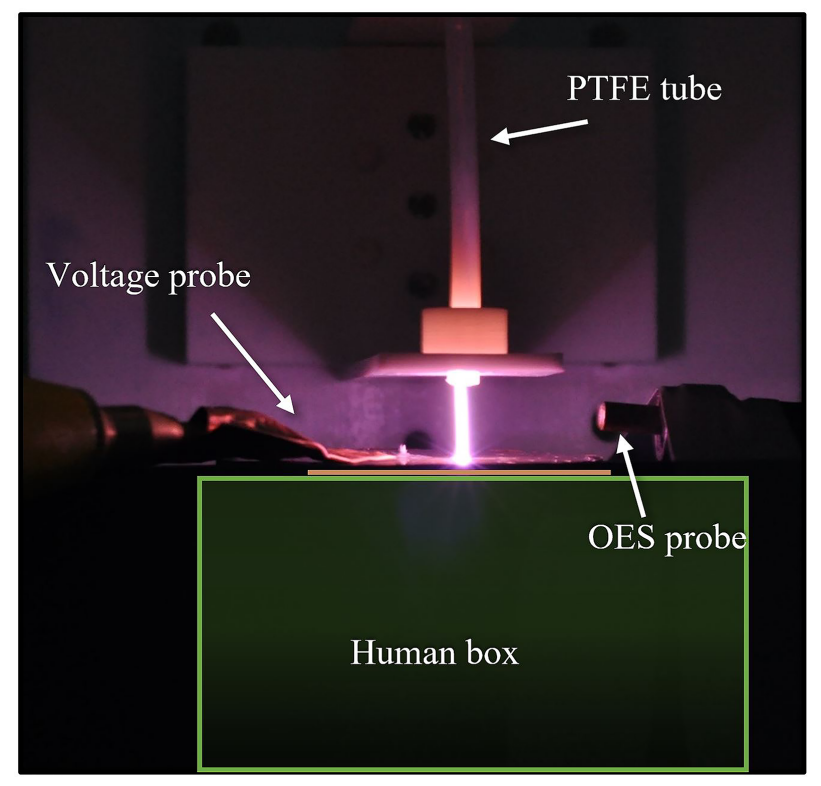

FIG. 4: Probe position at the tip of the capillary 


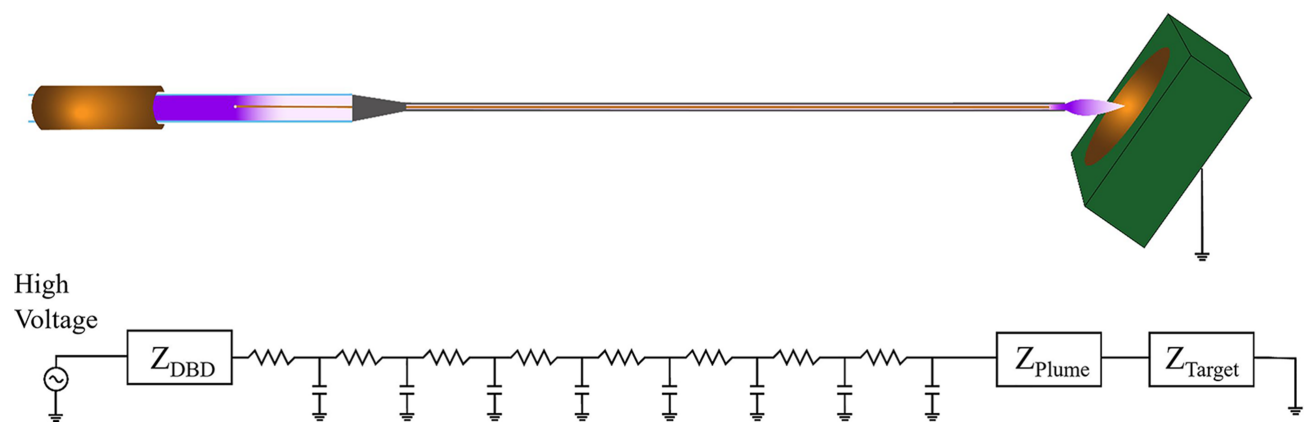

FIG. 5: Model based on transmission line electrical element behavior

therefore, transmission line-related theory can be used to model and understand, from an electrical point of view, the capillary of our system, as represented in Fig. 5. A transmission line is generally modeled as a two-port distributed-element circuit designed to conduct alternating current of radio frequency. ${ }^{32-34} \mathrm{~A}$ distributed element means that the primary constants of the system (resistance and inductance along the line, and conductance and capacitance shunting the line) are all specified per unit of length. The load circuit (in this case the plasma plume impedance $Z_{\text {Plume }}$ and the target impedance $Z_{\text {Target }}$ ) will greatly influence power losses through the transmission line. Therefore, there will be two possible configurations: either the load impedance is large and the transmission line behaves as in open circuit (e.g., in free jet, when the $Z_{\text {Target }}$ value is important), or the load impedance is small enough to form a preferential path for the current $\left(Z_{\text {Plume }}\right.$ and $Z_{\text {Target }}$ are both small). In the present work, the qualitative model allows us to interpret experimental results and highlight some trends in those results.

\section{RESULTS}

The results are divided into four categories: impact of the input power, impact of the gap distance between capillary and target, evolution of the current along the tube, and description of the system used in an endoscope. When relevant, two configurations are studied: the human box, with the plume being applied to it; and the free jet, with the plume in open air only. In order to compare experiments, reference curves (Fig. 6) were recorded using standard parameters (as described in the previous section) for both configurations.

In the presence of the box, the current along the PTFE tube and the current at the plume are similar in shape and amplitude, with an RMS current of $9.3 \mathrm{~mA}$ and $9.2 \mathrm{~mA}$, respectively, showing that most of the current that flows inside the tube is transferred to the plume in this configuration.

In free-jet mode, for the same input power, we observe a slightly higher input voltage (9.6 kV peak voltage compared to $7.6 \mathrm{kV}$ with the box) but a lower current flowing 


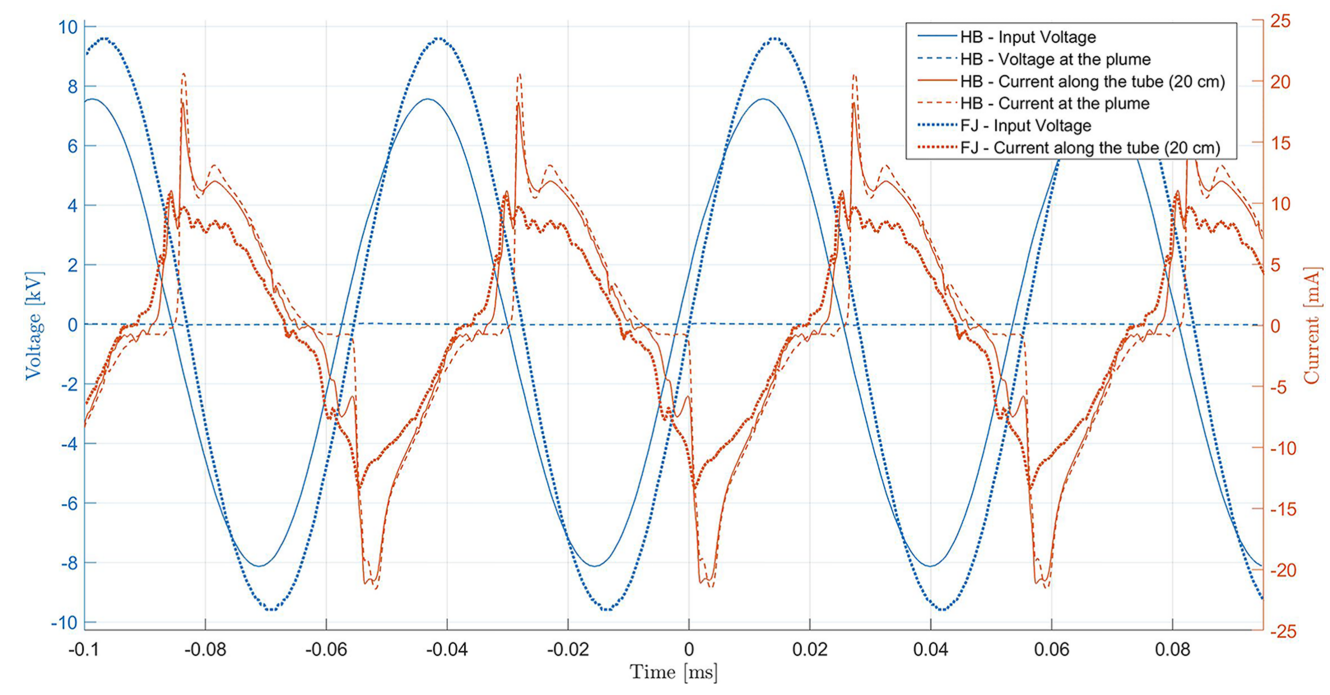

FIG. 6: Reference electrical waveforms obtained with standard parameters (50-W applied power, $18-\mathrm{kHz}$ frequency) in the human-box (HB) and free-jet (FJ) configurations

inside the PTFE tube ( $6.9 \mathrm{~mA} \mathrm{rms})$. Since the impedance seen by the generator is large in free-jet mode because of the absence of the low impedance path at the outlet of the tube (i.e., in human-box mode), we suggest that a significant part of the current is lost through the PTFE tube wall because of capacitive leakage.

Indeed, when the plasma plume is impinging the human box, the electrical impedance at the outlet of the tube is relatively low (i.e., lower than that due to capacitive coupling at the PTFE) and almost all the current can flow through the box. In contrast, the free-jet configuration is electrically closer to an open circuit since the outlet of the tube has a relatively high impedance (i.e., much higher than that in the human-box configuration), explaining the reduced current into the tube and the higher leakage current flowing through the capacitive coupling along the tube. This supports the work of Stancampiano et al. ${ }^{28}$ showing that the plasma is a dynamic system and underlining the importance of running tests in conditions close to the final application (e.g., with an impedance mimicking the human body). A last difference between the configurations lies in the shape of the current peaks observed with and without the human box, suggesting different plasma regimes.

\section{A. Impact of the Input Power}

The effect of the change in input power on both the current in the system and the amount of reactive species produced is investigated for both configurations (free jet and human box). Figure 7 shows that impact on the plume aspect in free-jet mode and in human-box mode.

Volume 10, Issue 2, 2020 

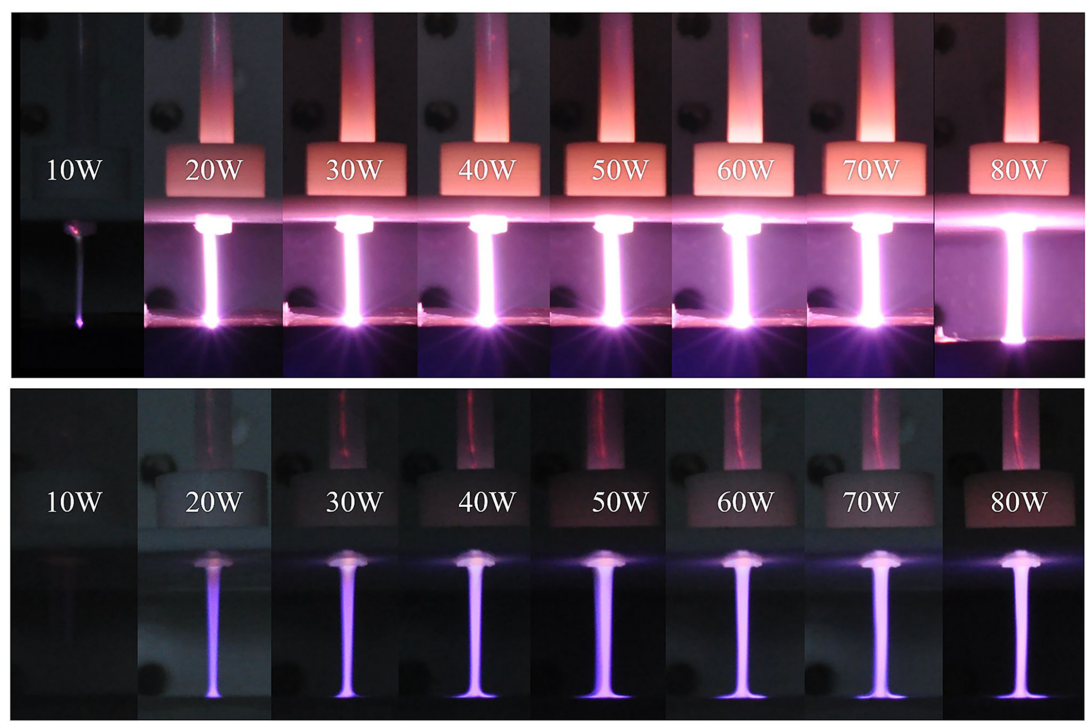

FIG. 7: Capillary tips as a function of input power in the human-box configuration (top) and the free-jet configuration (applied on a PMMA dielectric block) (bottom)

When increasing the input power, the input voltage increases as expected, ranging from $4.5 \mathrm{kVpp}$ to $8.8 \mathrm{kVpp}$, for an input power ranging from $10 \mathrm{~W}$ to $80 \mathrm{~W}$, respectively, in the human-box configuration and from $4.8 \mathrm{kVpp}$ to $11.8 \mathrm{kVpp}$ in the free-jet configuration.

In the human-box configuration, the current along the tube and that inside the plume (Fig. 8) both increase and a change in waveform can be observed due to the ignition of the plasma. Indeed, below $20 \mathrm{~W}$ (at $20 \mathrm{~W}$, the plasma plume switches from fully glowing to slightly ignited), no current is measured through the human box although the capillary tip is slightly glowing (Fig. 7). Above $20 \mathrm{~W}$, because of the increase in charge density, a substantial plasma plume is created, which decreases gap resistivity by establishing an electrical connection (i.e., drastically reducing the $Z_{\text {Plume }}$ value of our model) between the tube outlet and the box. A current can then be measured, roughly equal to the current through the plume or through the human box (see Fig. 10), and the current waveform is presenting the peak corresponding to the discharge.

In the free-jet configuration, the amplitude of the current inside the tube, as expected, increases with the input power but no other waveform change is observed (Fig. 9) since there is no "electrical connection" regime switch as there is in the human-box configuration. Visually, this higher current along the capillary results in a plume glowing more intensely (Fig. 7) without any other significant change.

Finally, Fig. 10 presents a comparison of the input power influence on RMS current along the tube and at the plume. When the plasma is fully ignited (above $20 \mathrm{~W}$ ), the current is significantly higher in the human-box configuration. This change in plasma electrical behavior and related electron density directly impacts the generation of RS, 

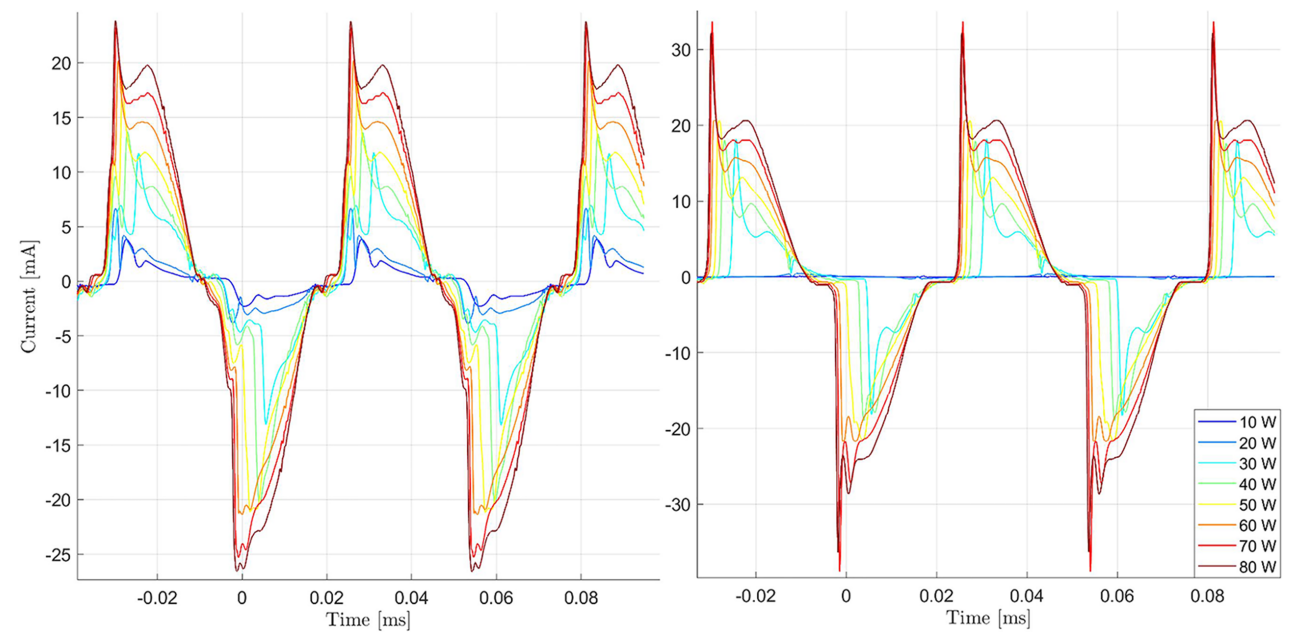

FIG. 8: Power influence on the current waveform in the human-box configuration: (left) along the tube (20 cm from high voltage); (right) at the plume

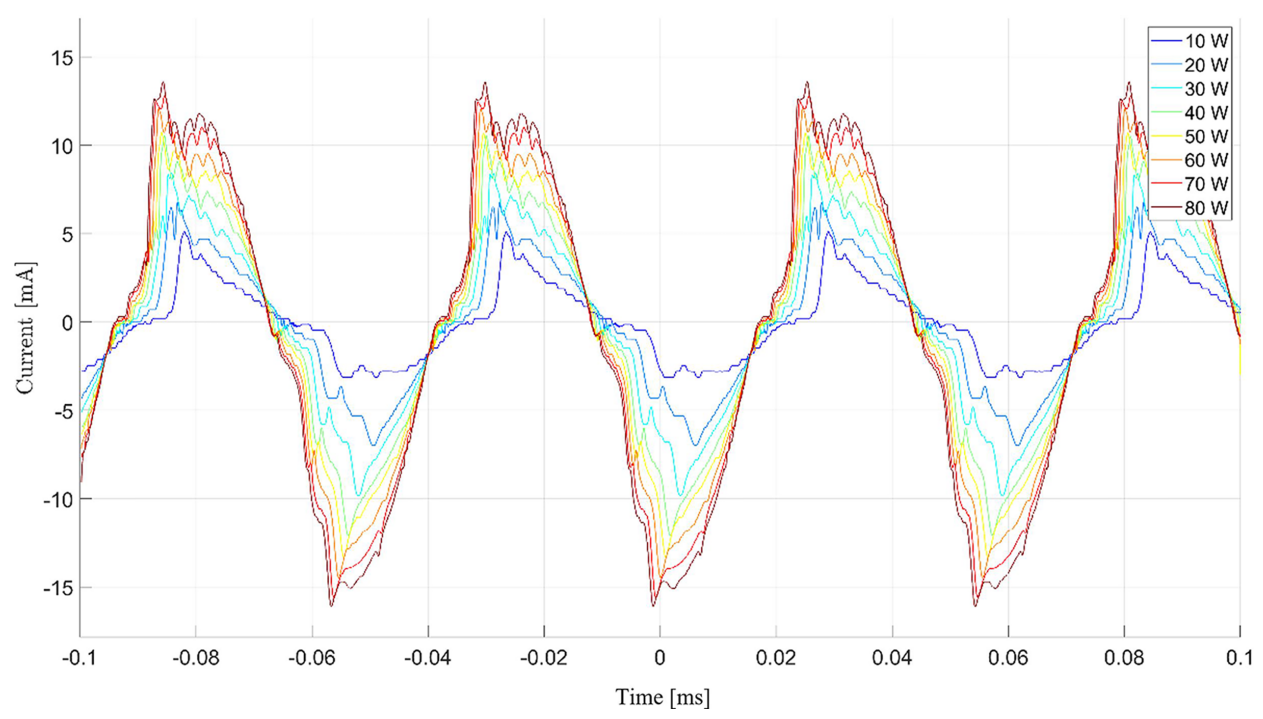

FIG. 9: Power influence on current waveform along the tube (20 $\mathrm{cm}$ from high voltage) in the free-jet configuration

which are qualitatively measured via optical emission spectroscopy. Figure 11 presents the intensities (in log scale) of selected relevant emission lines or bands as a function of plasma power for the free-jet and human-box configurations. As shown in Fig. 7, plasma plumes in the human-box configuration exhibit much higher light emission intensities accounting for much higher RS production than in the free-jet configuration. 


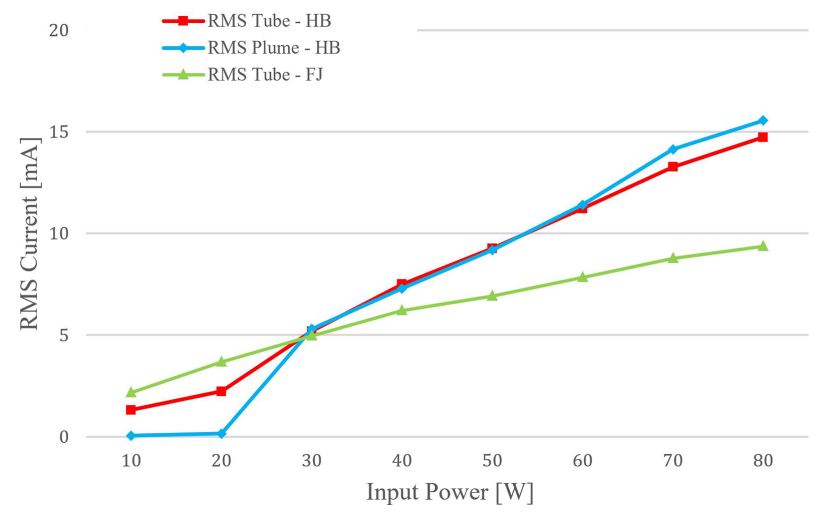

FIG. 10: RMS current (along the tube and at the plume) as a function of input power with and without the human box

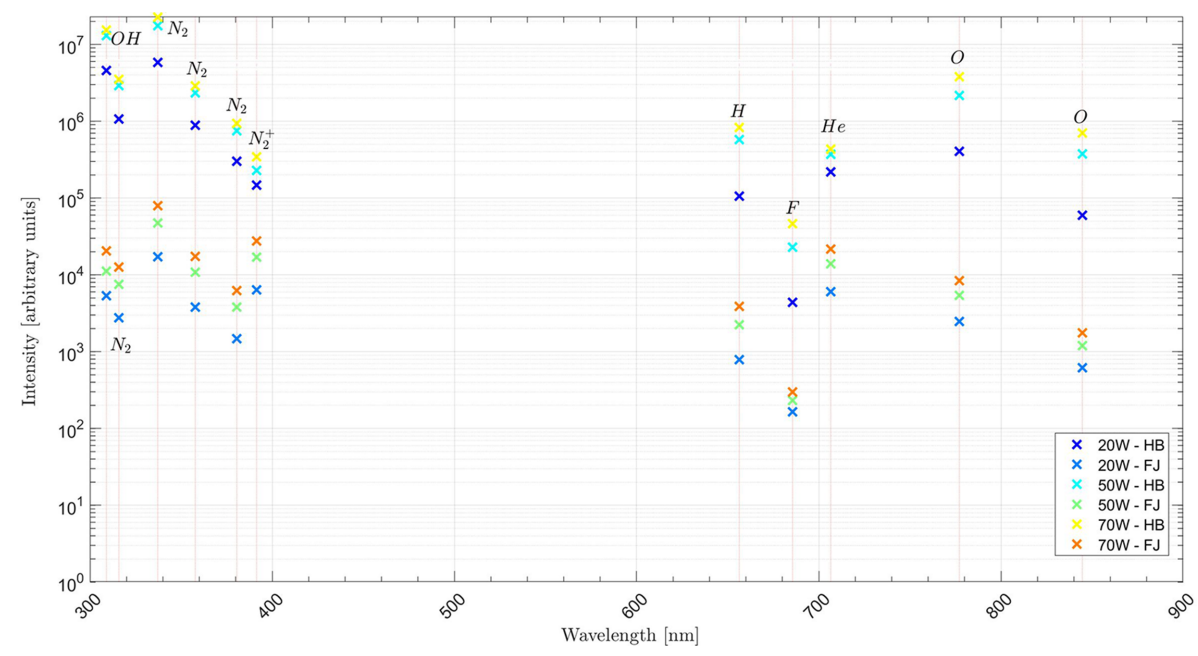

FIG. 11: Optical emission spectra: visualization of peak intensities

Differences in emission line intensities between the two configurations can indeed reach three orders of magnitude. Figure 7 also shows the increase in specific reactive species such as atomic oxygen $(777.4 \mathrm{~nm})$ or hydroxyl radical $(309.0 \mathrm{~nm})$ that are known to be of interest for cell treatment. ${ }^{6}$

\section{B. Impact of the Gap Distance between the PTFE Tube and the Human Box}

The previous section showed how input power can modify the $Z_{\text {Plume }}$ value, but another parameter linked to this value is the gap distance to the target, which can easily vary in 
medical applications such as endoscopy. The influence of the gap distance between the capillary and the target on the breakdown voltage and the plasma regime is assessed by varying its value from $0.5 \mathrm{~cm}$ to $2.5 \mathrm{~cm}$ in steps of $0.5 \mathrm{~cm}$ (these are expected realistic distances for real endoscopy treatments). Figure 12 shows the plasma plume for input powers of $50 \mathrm{~W}$ and $60 \mathrm{~W}$. At $60 \mathrm{~W}$ and a gap distance of $2 \mathrm{~cm}$, the plasma oscillates between two states: fully glowing (as shown at left) and hybrid plume, similar to the free-jet configuration (at right). For an input power of $50 \mathrm{~W}$, this transitional oscillating situation happens over a shorter gap distance.

Figure 13 shows the current waveforms along the tube and at the plume, which confirm this behavior. Indeed, at $60 \mathrm{~W}$ and for a gap of $2 \mathrm{~cm}$ or greater (middle curved lines), the current measured through the human box is very small (and is probably due to electromagnetic interference through the Pearson Rogowski probe) compared to the current measured for smaller gaps. Consistently, the current along the tube $(8.2 \mathrm{~mA} \mathrm{rms}$ at $60 \mathrm{~W}$ and $7.4 \mathrm{~mA} \mathrm{rms}$ at $50 \mathrm{~W}$ ) is similar to the current along the tube in the free-jet configuration ( $7.8 \mathrm{~mA} \mathrm{rms}$ and $6.9 \mathrm{~mA} \mathrm{rms}$, respectively) toward which it reaches as the gap increases. This suggests that the current peaks, which are only observed for short distances, in the waveform of the plasma plume current are reflecting the fully glowing behavior of the plasma. The shape of the current curve for short gap distances (Fig. 13) reveals an asymmetric behavior between the positive and negative waves, with a single intense peak for positive currents and multiple peaks in the negative range. At greater gap distances, the current curves flatten much more, suggesting a different plasma regime. Figure 14 summarizes the RMS current values for each distance and highlights the transition between the fully glowing state (touching the box) with small $Z_{\text {Plume }}$ and $Z_{\text {Target }}$

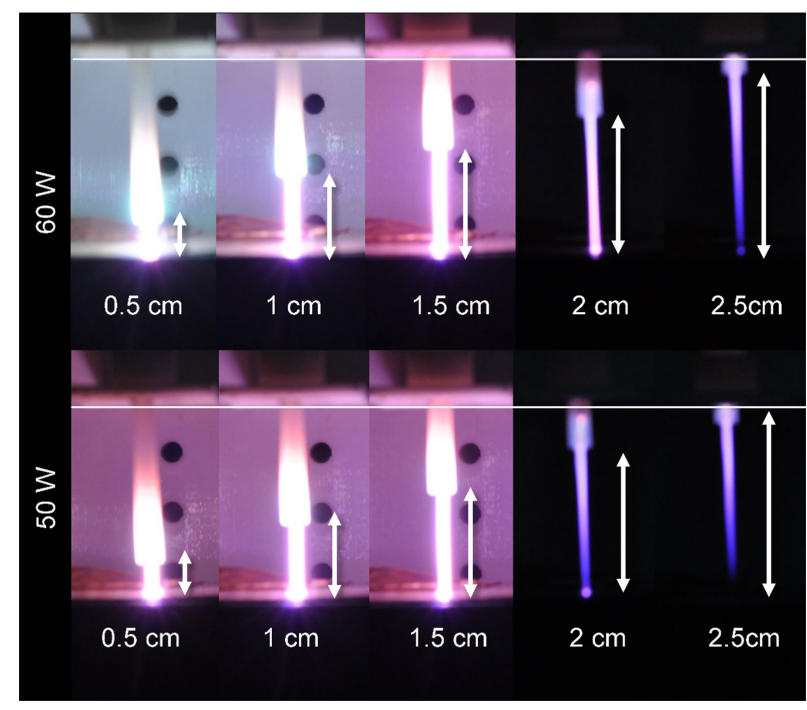

FIG. 12: Plume for several gap distances between the plume and the human box for input powers of $60 \mathrm{~W}$ (top) and $50 \mathrm{~W}$ (bottom)

Volume 10, Issue 2, 2020 

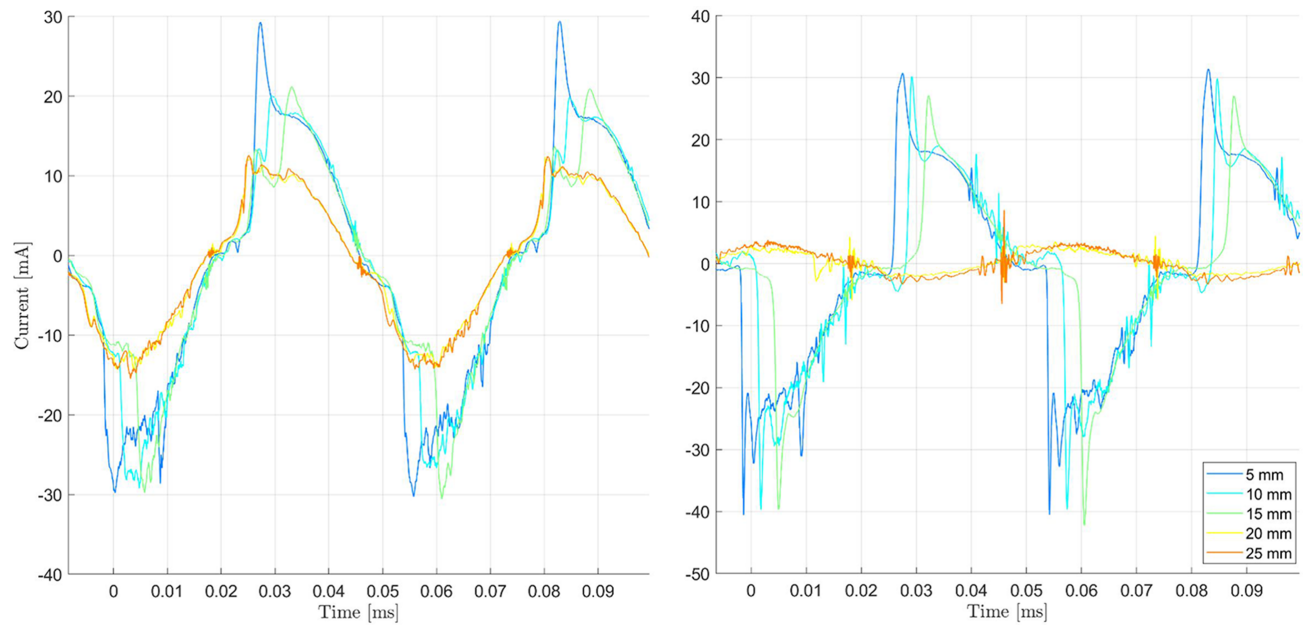

FIG. 13: Current waveform along the tube (left) and at the plume (right) for several gap distances between the capillary tip and the human box $(60 \mathrm{~W})$

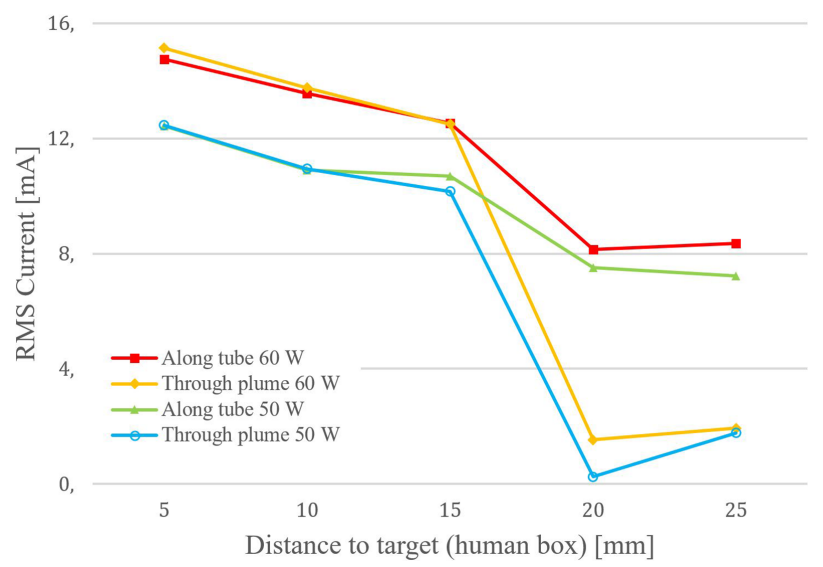

FIG. 14: RMS current along the tube and at the plume obtained with different gap distances between the capillary tip and the human box

values, and the free-jet-like state (the box is too far away for an electrical connection to be established) for which $Z_{\text {Plume }}$ is significant.

The intensities of the emission lines (or bands) of the main active species detected by OES are shown in Fig. 15 plotted as a function of each gap distance. Again, two domains can be observed: those at short distances, corresponding to fully glowing (or electrically connected) discharge high-intensity emission lines, and those observed at greater distances (20 or $25 \mathrm{~mm}$ ), corresponding to emission lines that exhibit much smaller intensities (by three orders of magnitude). 


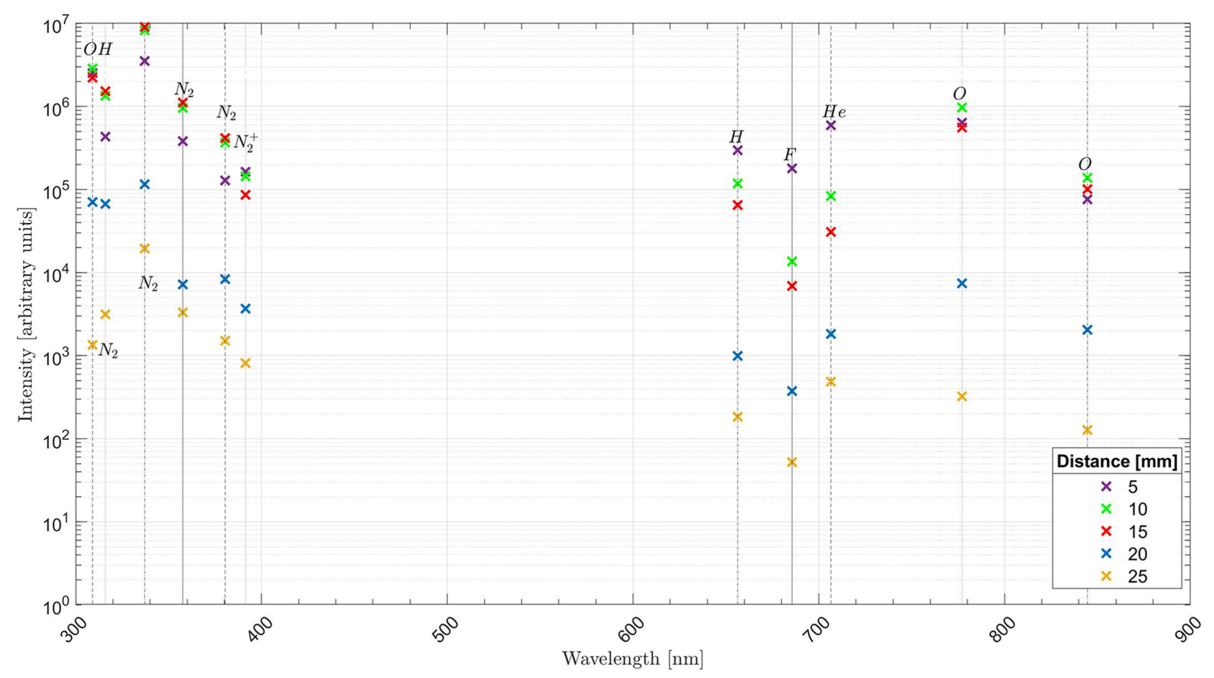

FIG. 15: OES (peak intensity) of the plasma plume for different gap distances between the capillary tip and the human box $(60 \mathrm{~W})$

Specific behaviors are also identified. Helium and fluorine (coming from the PTFE tube) OES intensities are at their highest for the smallest gap $(5 \mathrm{~mm})$ and exponentially decrease with distance. The presence of fluorine reveals a partial degradation of the capillary tube due to the interaction with metastable helium (as shown by Hubert et al.), ${ }^{35}$ and should be overcome for in vivo applications. Secondary reactive species are more present when the gap distance increases because the concentration of oxygen and nitrogen species increases with distance through the mixing of the plume and ambient air. Then, by extending this distance further, the amount of emitting species logically decreases because the plasma plume loses intensity and electron density when the connection with the human box is lost.

\section{Evolution of the Current along the Tube}

While the currents in the tube and at the plume are similar in the human-box configuration, the free-jet configuration should show a different behavior because, according to our model, its end is electrically closer to an open circuit, forcing the current through capacitive leakages that result in an important difference between the current in the tube and at the plume. The current evolution along the tube in the free-jet and human box configurations is measured.

When the plasma is impinging on the human box and the system approaches a closed circuit, no decrease in current intensity as a function of the measuring spot (at left in Fig. 16) can be observed. The only change observed is a slight change in the current waveform shape around zero, which is not reflected in RMS current values (see $20 \mathrm{~cm}$ mark in legend of Fig. 18). In the free-jet configuration, as expected with capacitive losses through the dielectric wall, the current is decreasing along the PTFE tube of a

Volume 10, Issue 2, 2020 

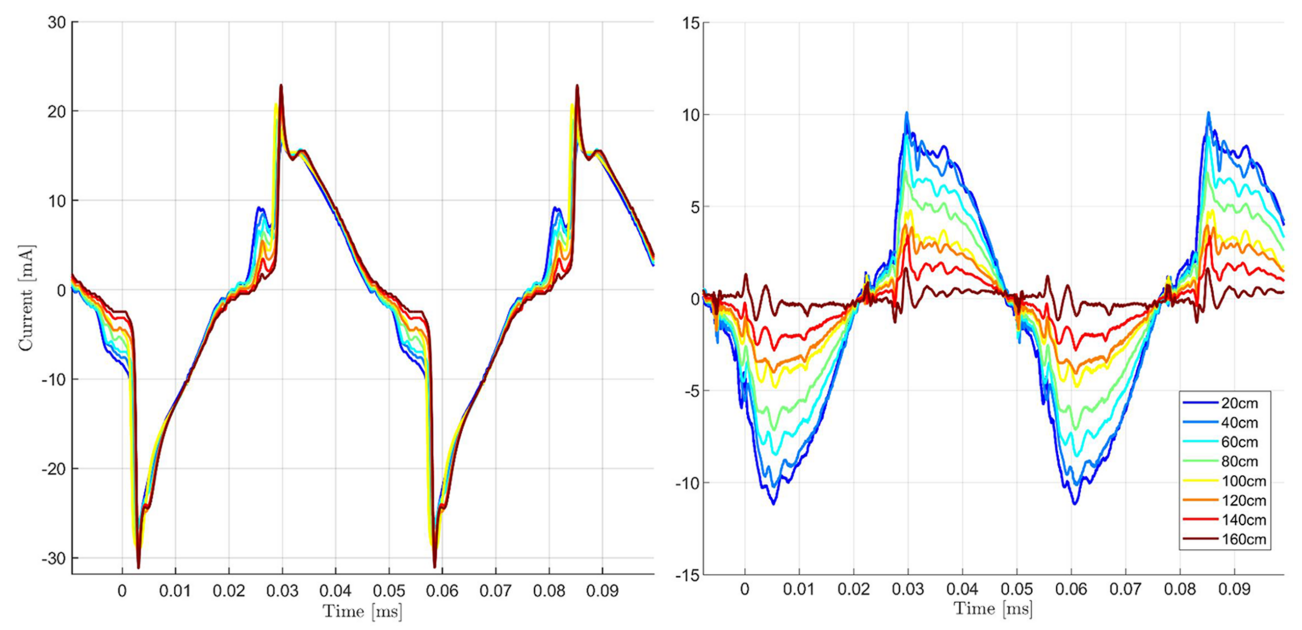

FIG. 16: Current waveform along the capillary at several measurement points from high-voltage electrode in the human-box (left) and free-jet (right) configurations

180 -cm-long device. To better understand this phenomenon, the same experiment is conducted for different devices with total tube lengths ranging from $60 \mathrm{~cm}$ to $2.2 \mathrm{~m}$ in steps of $20 \mathrm{~cm}$. The results, achieved by computing RMS current, are summarized in Fig. 17.

For each total tube length, the current measured along the tube decreases linearly (with an average slope of $0.06 \mathrm{~mA} / \mathrm{cm}$ ) as the measure point moves away from the highvoltage electrode, demonstrating the existence of a leakage current with a relatively constant value per unit of length. This is in good agreement with our model. The behavior of all curves is very similar, with a constant slope of current loss per centimeter. Interestingly, the lowest current point of each curve, corresponding to the current measured at $20 \mathrm{~cm}$ of the plasma plume, remains in the same relatively low range across different tube lengths, going from $1.2 \mathrm{~mA}$ to $0.3 \mathrm{~mA}$. In contrast, the highest current point of each curve (i.e., the current just after the high voltage) varies from $3.1 \mathrm{~mA}$ to $7.7 \mathrm{~mA}$.

This can be explained by the aforementioned capacitive losses through the PTFE tube walls. Longer tubes mean longer capacitors (i.e., walls), which decrease the total impedance of the system. For a constant input power $(50 \mathrm{~W})$, lower impedance means higher current (since the voltage at the source ranges from $9.8 \mathrm{kVpp}$ for the longest tube length to $11.4 \mathrm{kVpp}$ for the shortest and the product 'voltage times current' at the source is constant). Thus is explained the higher starting current for longer tubes. These linear losses by capacitive effect confirm the transmission line element hypothesized in our model for the tube carrying the plasma.

Figure 18 summarizes the effect of the target impedance on the current in the tube (for several measurement points) with a comparison of the evolution of RMS current along the tube between the two configurations (human box and free jet). This shows that, since the impedance of the human box is lower than the impedance of the tube, the current in the human box configuration is higher (lower impedance) and constant along 


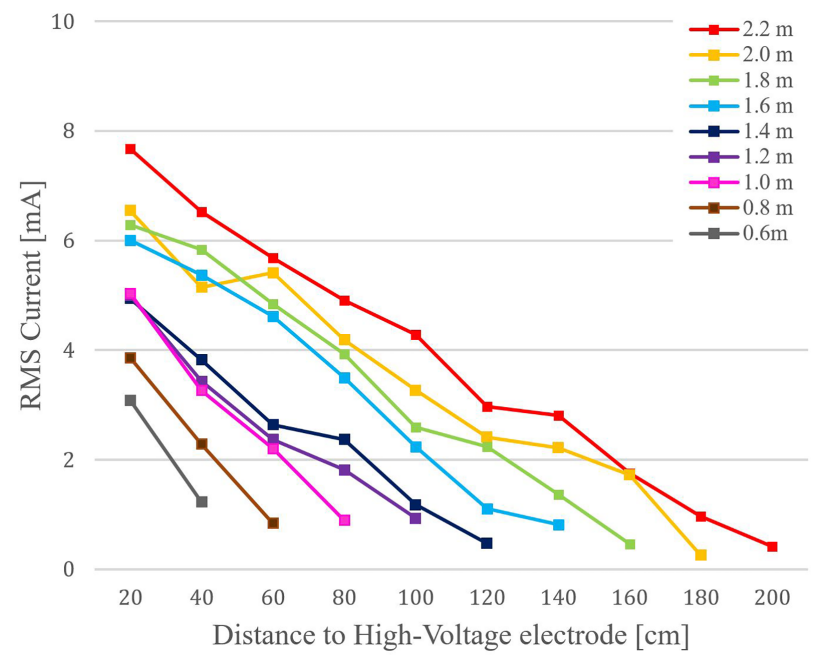

FIG. 17: RMS current along the tube measured at several distances from high-voltage electrode for different total capillary lengths in the free-jet configuration (see legend)

15

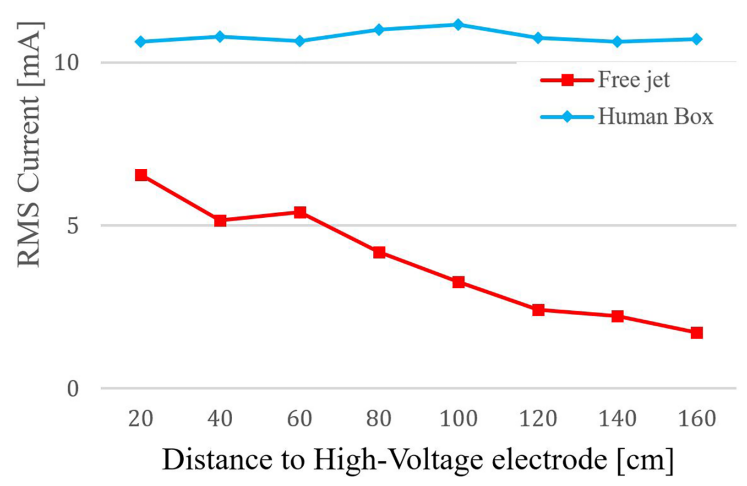

FIG. 18: RMS current along the tube measured at several distances from the high-voltage electrode for the free-jet configuration and the human-box configuration

the tube (no capacitive leaks through the transmission line), which is in contrast to the free-jet configuration.

\section{Description of the System Used in an Endoscope}

As the device presented in this article is to be used with an endoscope, this section presents its behavior when the capillary is inserted inside the endoscope's working channel 
(as schematically represented in Fig. 19). This arrangement therefore illustrates a practical clinical application. In it the Pearson Rogowski coil is positioned around the endoscope itself.

Figure 19 visually compares, for several input powers, the plasma plume applied on the human box when the capillary is inserted into the endoscope with the standard parameters. The behavior of the tube running in the endoscope is similar, but higher power is needed to obtain the transition between the free-jet-like plume and the fully glowing plasma. This can be explained by the reduced impedance of the capacitive paths along the tube. Indeed, as the endoscope is made of various conductive parts, its working channel, which is in contact with the tube along its whole length, represents a facilitated pathway for capacitive leaks. Figure 20 illustrates the vision typically obtained with the endoscope when the plasma is ignited and applied to the human box.

Current waveforms (along the endoscope and at the plume in Fig. 21) with the endoscope also show that the input power applied has to be higher than $50 \mathrm{~W}$ to observe a significant current passing through the human box by establishing the electrical connection described in sections A and B. For these powers, the current shows substantially constant
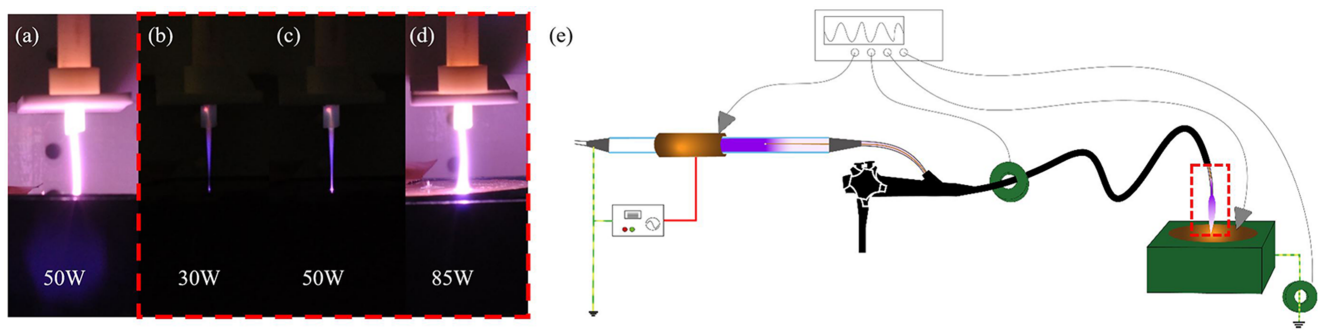

FIG. 19: Plume without the endoscope (a) and when the capillary is inserted into the endoscope (b, c, and d) for three input powers, as illustrated in the scheme (e). The dashed rectangle in (e) shows the setup part taken in (b, c, and d).
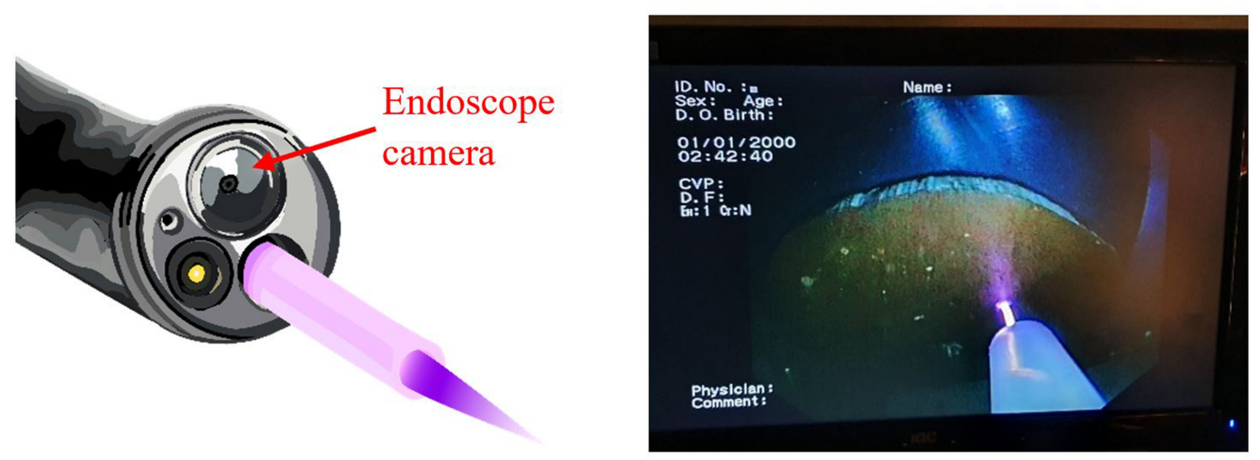

FIG. 20: (left) Schematic of the endoscope distal end and (right) plume applied in the humanbox configuration, recorded by the endoscope camera 

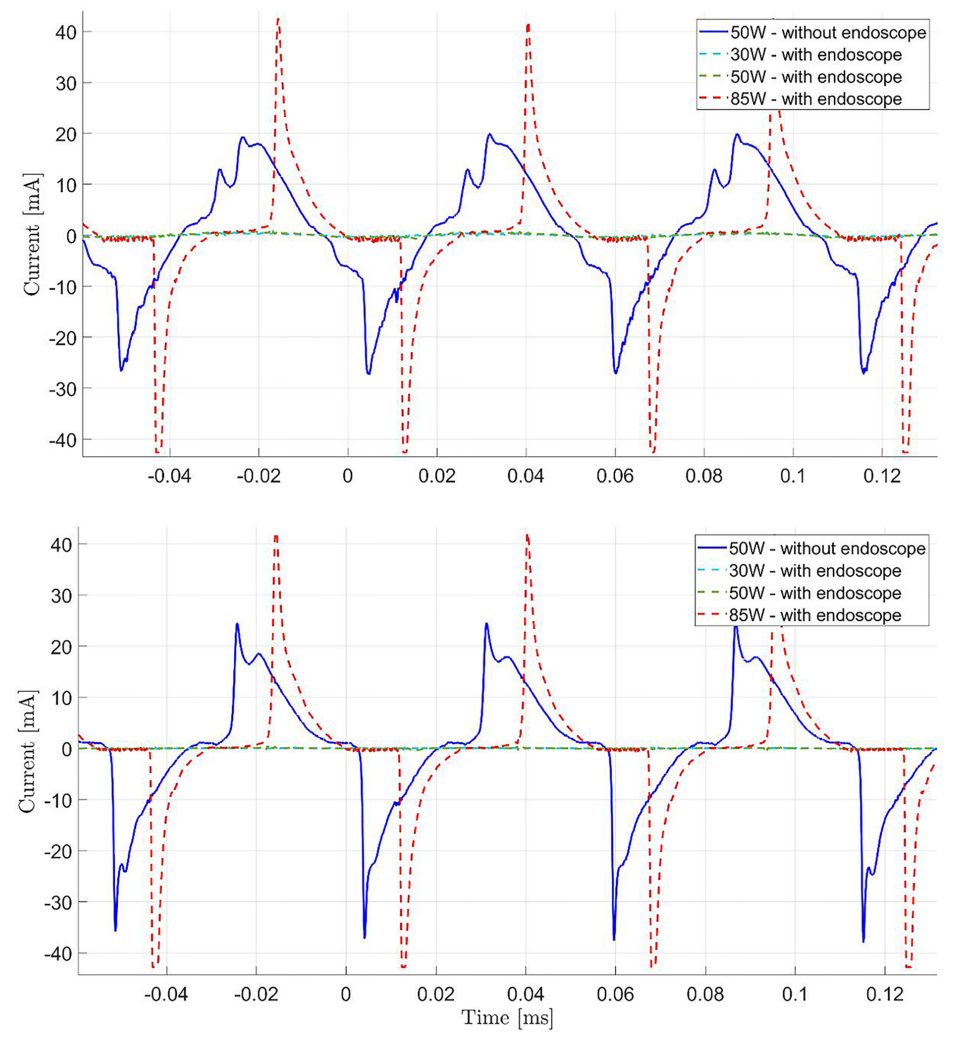

FIG. 21: Current waveform (top) through the system (endoscope and capillary) and (bottom) at the plume when the capillary is inserted inside the working channel of an endoscope

amplitude and shape along the tube, which is recommended for stability and predictability in medical applications. Indeed, when the capillary is inserted into the endoscope, the shape of the current curve reveals, for both negative and positive current, a single peak, suggesting a homogeneous well-known DBD behavior. Except for the changes in ignition power and current shape, no unexpected plasma or endoscope behavior is observed, highlighting the compatibility of our plasma system with an endoscope.

\section{DISCUSSION AND CONCLUSION}

This study describes and characterizes a plasma-source design that delivers cold atmospheric plasma through an endoscope over at least $2 \mathrm{~m}$ with the high-voltage electrode outside the patient's body. The plasma transport over this long distance is made possible by a floating metallic wire that renders the application compatible with all types of flexible endoscopes currently used in clinical practice.

The electrical characterisation of the plasma source presented in this paper highlights several characteristics of a long capillary plasma jet:

Volume 10, Issue 2, 2020 
- As is true of every cold atmospheric plasma source, ${ }^{12,36}$ its behavior is highly dependent on its surroundings and, more specifically, on the target to which the plasma is applied (and its impedance $Z_{\text {Target }}$ ). The plume-target gap distance (and the geometry of the capillary tip itself) and the input power are therefore also of high importance because they impact the switch from one configuration (free jet) to the other (human box) by acting on the $\mathrm{Z}_{\text {Plume }}$ value.

- Such a long plasma jet device seems to behave like a transmission line and could be modelled as such. When its end is similar to an open circuit, most of the current is leaked by capacitive coupling through the PTFE tube (as in the free-jet configuration). Conversely, the current is transmitted with almost no leaks when the circuit is closed by the fully glowing plasma, which drastically reduces the impedance of the gap and electrically "connects" the capillary to the human box (low $Z_{\text {Plume }}$ and $Z_{\text {Target }}$ ).

- The addition of an endoscope increases the current leaks along the tube. Indeed, as the endoscope is made of conductive parts, its impedance is smaller than the air surrounding the "naked" tube. Consequently, higher input power is needed to produce a plasma plume and a fully glowing plume.

The electrical characterization of the plasma source described here provides, in this regard, a first step toward prediction and thus control of the current flowing into the patient - a key parameter directly linked to patient safety but also influencing the effect of the plasma on the patient and hence the therapy.

Based on our proposed qualitative model, we are currently working on the implementation of a quantitative model with a fully characterized electrical equivalent circuit (having numerical values for $Z_{\text {Plume }}, Z_{\mathrm{DBD}}$, and $Z_{\text {Target }}$ ). This model will help us design the kind of predictable, stable, and safe system that is mandatory in the medical domain.

Optical characterization allows extraction of information crucial to the design of a medical plasma jet device as it highlights an optimum (for one input power) in terms of gap distance (about $10 \mathrm{~mm}$ ) to produce certain reactive species in the approaching human body behavior. More knowledge of the spatial distribution of reactive species for studying the effect of plasma on cells is essential to understanding the underlying mechanisms in vitro.

Our device is not ready to be used immediately in clinical practice, as it requires further refinements, particularly with testing of other high-voltage input shapes that increase the generation of ROS for the same input power. ${ }^{37,38}$ Our experiments show the importance of integrating all devices (endoscopes, guide wire, etc) with which the plasma jet can interact into the characterization and development of a new cold plasma jet medical device for flexible therapeutic endoscopy.

\section{ACKNOWLEDGMENTS}

This work was funded by the Michel Cremer Foundation and by the Université Libre de Bruxelles. The authors would like to acknowledge the contribution of medical writer, 
Sandy Field, $\mathrm{PhD}$, for formatting and for editing the English-language version of the manuscript.

\section{REFERENCES}

1. Vasilets VN, Gutsol A, Shekhter AB, Fridman A. Plasma medicine. High Energy Chem. 2009;43(3):229-33.

2. Fridman G, Friedman G, Gutsol A, Shekhter AB, Vasilets VN, Fridman A. Applied plasma medicine. Plasma Process Polym. 2008;5(6):503-33.

3. Kong MG, Kroesen G, Morfill G, Nosenko T, Shimizu T, Van Dijk J, Zimmerman JL. Plasma medicine: An introductory review. New J Phys. 2009;11:115012.

4. Keidar M, Walk R, Shashurin A, Srinivasan P, Sandler A, Dasgupta S, Ravi R, Guerrero-Preston R, Trink B. Cold plasma selectivity and the possibility of a paradigm shift in cancer therapy. Br J Cancer. 2011;105(9):1295-301.

5. Kalghatgi SU, Fridman G, Fridman A, Friedman G, Clyne AM. Non-thermal dielectric barrier discharge plasma treatment of endothelial cells. In: 2008 30th annual international conference of the IEEE Engineering in Medicine and Biology Society, Vancouver, BC, 2008; p. 3578-81.

6. Graves DB. The emerging role of reactive oxygen and nitrogen species in redox biology and some implications for plasma applications to medicine and biology. J Phys D Appl Phys. 2012;45:263001.

7. Yan D, Sherman JH, Keidar M. Cold atmospheric plasma, a novel promising anti-cancer treatment modality. Oncotarget. 2017;8(9):15977-95.

8. Isbary G, Morfill G, Schmidt HU, Georgi M, Ramrath K, Heinlin J, Karrer S, Landthaler M, Shimizu T, Steffes B, Bunk W, Monetti R, Zimmerman JL, Pompl R, Stolz W. A first prospective randomized controlled trial to decrease bacterial load using cold atmospheric argon plasma on chronic wounds in patients. Br J Dermatol. 2010;163(1):78-82.

9. Kurosawa M, Takamatsu T, Kawano H, Hayashi Y, Miyahara H, Ota S, Okino A, Yoshida M. Endoscopic hemostasis in porcine gastrointestinal tract using $\mathrm{CO} 2$ low-temperature plasma jet. J Surg Res. 2019;234:334-42.

10. Foster KW, Moy RL, Fincher EF. Advances in plasma skin regeneration. J Cosmet Dermatol. 2008;7(3):169-79.

11. Weltmann KD, Kindel E, Brandenburg R, Meyer C, Bussiahn R, Wilke C, von Woedtke T. Atmospheric pressure plasma jet for medical therapy: Plasma parameters and risk estimation. Contrib Plasma Phys. 2009;49(9):631-40.

12. Helmke A, Gerling T, Weltmann KD. Plasma sources for biomedical applications. In: Metelmann HR, von Woedtke T, Weltmann KD, editors. Comprehensive clinical plasma medicine. Cham (Switzerland): Springer; 2018. p. 23-41.

13. Vassiliou MC, Von Renteln D, Wiener DC, Gordon SR, Rothstein RI. Treatment of ultralong-segment Barrett's using focal and balloon-based radiofrequency ablation. Surg Endosc Other Interv Tech. 2010;24(4):786-91.

14. Altonbary AY, Galal A, El-Nady M, Hakim H. Endoscopic ultrasound guided biliary drainage: A multicenter retrospective experience of a technique slowly gaining acceptance in Egypt. Ther Adv Gastrointest Endosc. 2019;12. doi: 10.1177/2631774519889456.

15. Kitamura K, Yamamiya A, Ishii Y, Mitsui Y, Yoshida H. Endoscopic side-by-side uncovered self-expandable metal stent placement for malignant hilar biliary obstruction. Ther Adv Gastrointest Endosc. 2019;12. doi: 10.1177/2631774519846345.

16. Cherrington AD, Rajagopalan H, Maggs D, Devière J. Hydrothermal duodenal mucosal resurfacing role in the treatment of metabolic disease. Gastrointest Endosc Clin N Am. 2017;27(2):299-311.

17. Everett SM. Endoscopic management of refractory benign oesophageal strictures. Ther Adv Gastrointest Endosc. 2019;12. doi: 10.1177/2631774519862134.

Volume 10, Issue 2, 2020 
18. Robert E, Vandamme M, Brullé L, Lerondel S, Le Pape A, Sarron V, Riés D, Darny T, Dozias S, Collet G, Kieda C, Pouvesle JM. Perspectives of endoscopic plasma applications. Clin Plasma Med. 2013;1(2):8-16.

19. Winter J, Nishime TMC, Bansemer R, Balazinski M, Wende K, Weltmann KD. Enhanced atmospheric pressure plasma jet setup for endoscopic applications. J Phys D Appl Phys. 2019;52(2):024005.

20. Konstantin KG, Machida M, Prysiazhnyi V, Honda RY. Transfer of a cold atmospheric pressure plasma jet through a long flexible plastic tube. Plasma Sources Sci Technol. 2015;24:025038.

21. Darny T, Pouvesle J, Puech V, Douat C, Dozias S, Robert E. Analysis of conductive target influence in plasma jet experiments through helium metastable and electric field measurements. Plasma Sources Sci Technol. 2017;26:045008.

22. Jõgi I, Talviste R, Raud J, Piip K, Paris P. The influence of the tube diameter on the properties of an atmospheric pressure He micro-plasma jet. J Phys D Appl Phys. 2014;47;415202.

23. Cho G, Lim H, Kim JH, Jin DJ, Kwon GC, Choi EH, Uhm HS. Cold plasma jets made of a syringe needle covered with a glass tube. IEEE Trans Plasma Sci. 2011;39(5):1234-8.

24. Robert E, Barbosa E, Dozias S, Vandamme M, Cachoncinlle C, Viladrosa R, Pouvesle JM. Experimental study of a compact nanosecond plasma gun. Plasma Process Polym. 2009;6(12):795-802.

25. Robert E, Sarron V, Riès D, Dozias S, Vandamme M, Pouvesle JM. Characterization of pulsed atmospheric-pressure plasma streams (PAPS) generated by a plasma gun. Plasma Sources Sci Technol. 2012;21:034017.

26. Winter J, Nishime TMC, Glitsch S, Lühder H, Weltmann KD. On the development of a deployable cold plasma endoscope. Contrib Plasma Phys. 2018;58(5):404-14.

27. Polak M, Winter J, Schnabel U, Ehlbeck J, Weltmann KD. Innovative plasma generation in flexible biopsy channels for inner-tube decontamination and medical applications. Plasma Process Polym. 2012;9(1):67-76.

28. Stancampiano A, Chung TH, Dozias S, Pouvesle JM, Mir LM, Robert E. Mimicking of human body electrical characteristic for easier translation of plasma biomedical studies to clinical applications. IEEE Trans Radiat Plasma Med Sci. 2019;4(3):335-42.

29. Judée F, Dufour T. Plasma gun for medical applications: Engineering an equivalent electrical target of the human body and deciphering relevant electrical parameters. J Phys D Appl Phys. 2019;52:16LT02.

30. Steer M. Modeling of transmission lines. In: Microwave and RF design: A systems approach. NC State University: Scitech Publishing; 2010. p. 178-94.

31. American Relay League. Chapter 20: Transmission lines. In ARRL handbook of radio communications [Internet]. 2010; Available from: http://www.eas.uccs.edu/ mwickert/ece3110/lecture_notes/ N3110_2.pdf.

32. Guru BS, Hiziroglu HR. Electromagnetic field theory fundamentals. 2nd ed. Cambridge: Cambridge University Press; 2009.

33. Lucht P. Transmission lines and Maxwell's equations. Salt Lake City: Rimrock Digital Technology; 2014.

34. Fowler B. Transmission line characteristics. Texas Instrum Note AN-108. 1986;(2):67-77.

35. Hubert J, Dufour T, Vandencasteele N, Desbief S, Lazzaroni R, Reniers F. Etching processes of polytetrafluoroethylene surfaces exposed to $\mathrm{He}$ and $\mathrm{He}-\mathrm{O} 2$ atmospheric post-discharges. Langmuir. 2012;28(25):9466-74.

36. Yousfi M, Merbahi N, Sarrette JP, Eichwald O, Ricard A, Gardou JP, Ducasse O, Benhenni M. Nonthermal plasma sources of production of active species for biomedical uses: Analyses, optimization and prospects. In: Biomedical engineering: Frontiers and challenges. InTech; 2011. p 99-124.

37. Walsh JL, Shi JJ, Kong MG. Contrasting characteristics of pulsed and sinusoidal cold atmospheric plasma jets. Appl Phys Lett. 2006;88(17):171501.

38. Laroussi M, Akan T. Arc-free atmospheric pressure cold plasma jets: A review. Plasma Process Polym. 2007;4(9):777-88. 